\title{
Reference Evapotranspiration Prediction for Smart Irrigation
}

\author{
Samer I. Mohamed
}

\begin{abstract}
Irrigation is the most critical process for agriculture, but irrigation is the largest consumer of fresh water and causes the loss of large quantities because of the inaccuracy in crop water estimation. Our proposed system aims to improve irrigation management by estimating the amount of water needed by the crop accurately and reduces the number of meteorological parameters needed for such estimation. Detection of the reference crop evapotranspiration (ETo) is the most critical process in crop water estimation, that is considered through our proposed solution by implementing machine learning models using neural networks and linear regression to predict daily ETo using climate data like temperature, humidity, wind speed, and solar radiation. Comparing our system results with FAO-56 Penman-Monteith ETO and cropwat8.0 software as benchmark, show that our proposed system is better than the linear regression model, in terms of determination coefficient $\left(R^{\wedge} 2\right)=.9677$ and root mean square error $(\mathrm{RMSE})=.1809$, while the multiple linear regression model achieved determination coefficient $\left(R^{\wedge} 2\right)=.68$ and root mean square error(RMSE) $=3.01$. Our system then used the predicted ETo and Crop coefficient (Kc) from FAO, to estimate crop evapotranspiration (ETc) for precision irrigation target.
\end{abstract}

Keywords: Evapotranspiration; machine learning; FAO_56; Neural network; predict; linear regression; irrigation.

\section{INTRODUCTION}

By 2050 the world's population will be 9 billion and demand for food will increase dramatically, Agriculture is the main source of food but consumes more than 70 percent of freshwater around the world. 25 percent from the water that used for irrigation is wasted because weakness in irrigation management. Most farmers irrigate crop without knowing the amount of water that plant needs at any real level of precision and this lead to waste a lot of irrigation water nevertheless the crop productivity is still weak. Thus, it is vital to develop a precision system to optimize irrigation management and predict the amount of water crop needs to decrease water consumption and increase crop productivity. In Egypt, agriculture is the main component for the economy; it represents more than 14.5 percent of the gross domestic product and 28 percent of entire jobs [7]. Small farms in Egypt dominate in agriculture approach and farmers use traditional practices like using old technology for irrigation so farmer suffers from increasing production cost, decreased soil fertility and insufficient water recourses [4].

Revised Manuscript Received on November 10, 2020.

* Correspondence Author

Samer I. Mohamed*, Associate Prof. October University for Modern Sciences and Arts MSA, saibrahim@msa.eun.eg

(c) The Authors. Published by Blue Eyes Intelligence Engineering and Sciences Publication (BEIESP). This is an open access article under the CC BY-NC-ND license (http://creativecommons.org/licenses/by-nc-nd/4.0/)
Most farmers irrigate crop without knowing the amount of water that plant needs at any real level of precision and this lead to waste a lot of irrigation water and productivity weak So it is important to develop a precision system to optimize irrigation management and predict the amount of water that crop needs to decrease water consumption \& increase productivity [8]. Two processes associated with high losses of water; the first process is evaporation; in this process water loss from soil, the second process is transpiration; in this process water loss from small openings on the plant leaf. Combined between these processes lead to know the amount of water that plant lost, and this process is evapotranspiration (ETo), and it is the main process to detect plant water needs. The goal of our study is developing system that can optimize effectively the water consumption by minimize water loss in irrigation. Our proposed system should predict the needed amount of water crop needs; Adjustment of water irrigation with weather parameters, along with continuous monitoring \& feedback for farm status [2]. To achieve the goals of this study, our proposed system will use supervised machine learning algorithms like multi linear regression and neural network to predict ETo by weather data using historical data. System will collect data related to weather by using weather sensors and send it to the prediction model to predict ETo. Thus, the proposed system mainly consists of two stages, first stage is monitoring, and second stage is prediction. In monitor stage, the system will monitor the parameters that that have impacts on crop and water needed using weather sensors distributed in the farm like temperature, humidity, wind speed and solar radiation, The second stage which is the prediction stage, the system will use data that collected from first stage to predict the amount of water crop needs based on machine learning algorithms [10].

\section{BACKGROUND}

The current approaches to set up water requirement prediction model depend only on climate information that coming from meteorological station, but there are some other problems with these approaches, like that all region doesn't have access to the precision weather information and if any sudden changes happen in climate, they cannot respond in real time [1]. Due to these technical limitations of accessible soil sensors, these approaches have not been widely accepted, requiring measurement data to be registered and stored, traditionally using wired, and limiting the flexibility and real-time interaction the sensors that unravel these issues have high cost, require uncommon treatment and require nonstop calibration.

Published By:

Blue Eyes Intelligence Engineering and Sciences Publication

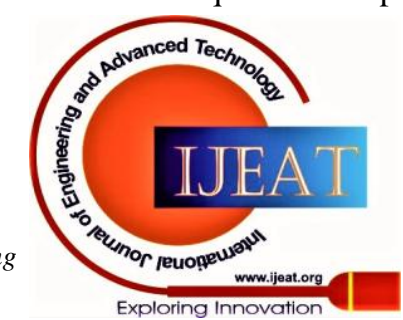




\section{Reference Evapotranspiration Prediction for Smart Irrigation}

The data gathered about soil status by using soil sensors can be used to build a better prediction model, monitoring all variables like soil moisture, the water quantity in the soil is important to predict water requirements correctly [5]. Combining between soil and climate variables will help in managing irrigation more efficiency from traditional approaches that use climate variables only [4]. The combination between these variables has some challenges like increasing amount data flow, traditional manual systems rely on agronomists expertise to help in irrigation management but it is not accessible to every farm, plenty of data will lead to slow in analysis and will impact in a real time processes. Thus, implementing machine learning models for prediction will help to predict crop water needs with high efficiency to bridge the current gap [9]. The most common methods to estimate evapotranspiration is experimental using lysimeter [11] or evaporation pan, but these systems are not accurate, need a lot of labor, and are very expensive. In the last years, scientists have developed numerous physical equations that used meteorological parameters to know reference crop evapotranspiration (ETo). The Food and Agricultural Organization of United Nations (FAO) has accepted the FAO Penman-Monteith (FAO-56PM) as the standard equation to estimate ETo (Allen et al., 1998). The climatic parameters that that have impacts on crop water needs are sunshine, wind speed, temperature, humidity, dew point, and pressure [6].

There are some other mathematical methods like Penman-Monteith, Makkink, Priestley-Taylor, Turc, Hargreaves-Samani, and Blaney-Criddle to calculate ETo but these models need high accuracy reading, and in many areas, the meteorological data set is not complete [3]. So the machine learning model helps to reduce the parameters that are needed to estimate reference evapotranspiration. Now, machine learning and deep learning are used widely in many fields of engineering and sciences like medicine, agriculture, and biochemistry [18]. These algorithms are used to improve and raise the accuracy of the prediction process depending on data sets come from many experiments in different fields [15]. This inspired and derive the design and implementation for our proposed system that aims to detect the amount of water the crop needs by using neural network based on deep learning from "Keras" library to predict ETo, and uses the crop coefficient "Kc" value come from FAO to predict the amount of water the crop needs [12].

\section{PROPOSED SYSTEM ARCHITECTURE}

Our system is based on FAO Penman-Monteith (FAO-56PM) equation as a benchmark to assess the accuracy of our proposed model and to compare our prediction results and the result used by FAO from using Penman-Monteith using CROPWAT8.0 program from FAO [20]. System will use then the predicted value of ETo to calculate the amount of water, the crop needs by multiple ETo and Kc. We also used different prediction models to achieve the best results, thus through our study, we compared between linear regression, neural network and FAO cropwat8.0 software to know what is the best model to predict reference evapotranspiration (ETo) and measure this using different metrics like determination coefficient $\left(\mathrm{R}^{\wedge} 2\right)$ and root mean square error(RMSE) [16].

We used Potato as the main crop for our proof of concept and case studies as in Egypt, the potato crop is one of the strategic vegetable crops, where about 200 thousand feddans

Retrieval Number: 100.1/ijeat.A18241010120 are grown each year, giving total productivity of about 1 million tons [13]. Potato plant is a cold air plant that needs its first stages of development (during the first two months of its life) to have a fairly warm atmosphere at a temperature of 25-20C [17]. Potato plant can be grown in different types of soil, but it is found in light tilapia and Algerian soil with good drainage and ventilation. It allows the growth of tubers to grow naturally to contain about $50-3$ clay and salts, about $2-3 \%$ of the sand [14]. To about $0.9 \%$ and the proportion of calcium carbonate to about $4 \%-2$ and if it is forced to cultivate in the new clay or heavy sandy land, care and attention should be given to organic and chemical fertilizers to improve their natural and chemical properties [19]. Potato crop of crops sensitive to the lack of soil moisture, especially during periods of critical growth of the plant. The soil moisture level must not be less than $60 \%$ of the available water [22]. This causes the shortage of the quantity of the crop and the small size and number of tubers produced. The periods are affected by the lack of soil moisture, which is about 6 - 5 weeks from the date of agriculture for the early varieties and 6: 8 weeks for the late varieties. The first irrigation is given after planting for 21-18 days, Soil conditions and plant growth stages [25]. The prevention of irrigation shall be taken before the reduction of about 7-10 days in the summer loaf, 15 - 10 days in the Nile and the Nile, in order to facilitate the cutting process and help to harden the crust and the soil is not stuck to tubers [19]. In the new lands, where irrigation system is drip or drip, it is necessary to give light and convergent irrigation (every 2-3 days) according to the prevailing weather conditions in the region and the stages of plant growth, to stop irrigation before the reduction by about 5 days [23]. In general Plant irrigation should be carried out either in the early morning or at sunset. According to $\mathrm{FAO}$, the Kc of potato is 0.5 in initial stage and it be in first 25 days, 1.15 in mid stage and in end stage $\mathrm{Kc}$ is 0.75 [21]. The weather data we used to train the neural network model for four years (2014 to 2018) from Cairo airport climate station with latitude 30.13, longitude 31.4, and altitude 64 [28]. The climate in Cairo is semi-arid; the range of minimum and maximum air temperature from 20 to $38 \mathrm{C}$ in summer and from 10 to $23 \mathrm{C}$, relative humidity is between 35 to $62 \%$, and maximum wind speed is 397 kilometers/day usually in May [30]. The weather data we used is consisting of the average of daily relative humidity; an average of daily air temperature, wind speed, and solar radiation, and these variables is input for neural network model. The proposed system as explained briefly in the previous sections compose of two main stages the first one for monitoring both the soil and meteorological parameters, and second phase is for predicting the amount of water crop needs for precision irrigation purposes.

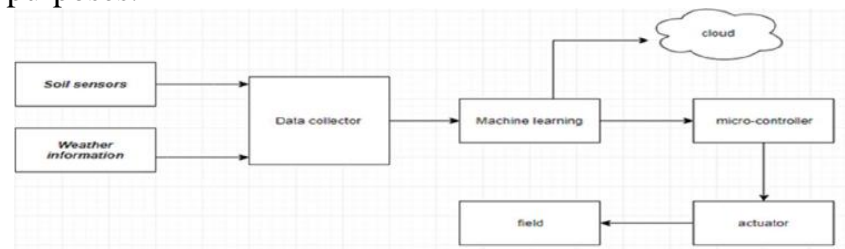

Fig. 1 Proposed system block diagram

Published By: Blue Eyes Intelligence Engineering and Sciences Publication (C) Copyright: All rights reserved.

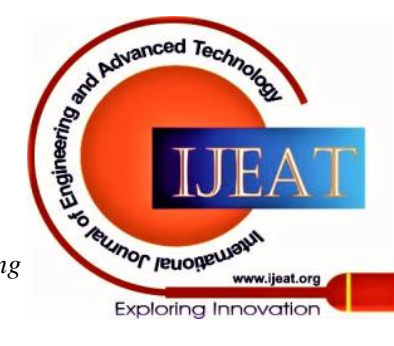


The block diagram as shown in Fig. 1 shows how these stages control and automate the crop irrigation process based on optimized irrigation schedule. Soil parameters that are measured from different soil sensor like matric potential and volumetric soil water content and the weather information that coming from weather station provide our machine learning model with relevant information for predicting the weekly irrigation schedule. This soil and meteorological data along with the weekly schedule data will be hosted on the cloud for analytics and dash boarding for farm management [29].

The proposed system used both Artificial Neural Network (ANN) and linear regression for building the prediction model. The advantages of the ANN is that it can learn and make complex relationships between nonlinear data [24], it can work in a massive amount of data and can process information rapidly. This study uses a ANN based on "Keras" [26] which is a deep learning library built in "Tensorflow" [27] from Google that it is characterized by fast operation and easy to handle. In our proposed system, the ANN consists of one input layer, two hidden layers, and one output layer. We used a rectified linear units (RELU) [35] as the strongest nonlinear activation function to build regression-based ANN, and because activation function is nonlinear [31], it is easy to backpropagate the errors, it allows to more natural optimization and faster than other activation functions. We also used adaptive moment estimation (ADAM) [33] as the optimization function to minimize the error and to improve the model. Feedforward, and Backpropagation method are used to train the neural network model because it is faster compared with any other optimizer [34].

The weather data consisted of 6 columns divided into five columns as inputs and one column as output, the input columns are maximum air temperature, minimum air temperature, the average relative humidity, wind speed, and solar radiation and the output column represents ETo. As such, to train the neural network model, data splits into two sections, the first section represents $70 \%$ from all of the data (875 samples, from 2014 to 2017) and it is used to train the neural network model [32]. The second section represents $30 \%$ from the data (375 samples, from 2017 to 2018) and it is used to test the training of neural network model and compare between the predicted value from machine learning and actual value from the weather data set. Our designed ANN is consisting of single input layer of 5 nodes based on the number of inputs variables, two hidden layers with 12 and 8 nodes respectively, and one single output layer with one node to predict the value of daily evapotranspiration. The value of ETo in the weather data of this study was calculated by Penman-Monteith equation [36], which calculates either hourly or daily ETo. The FAO Penman-Monteith method is integration between mass transfer method and energy balance with select reference surface resistance factors [40]. This method is a physical method depend on the equation of Penman-Monteith, and this equation clarifies that the reference surface is green grass hypothetical surface with a uniform height equal $0.12 \mathrm{~m}$, with a surface resistance equal 70 sm- 1 and an albedo equal 0.23 with good actively growing and enough watered conditions [37].

$$
E_{0}=\frac{0.408 \Delta\left(R_{n}-G\right)+\gamma \frac{900}{T+273} u_{2}\left(e_{s}-e_{a}\right)}{\Delta+\gamma\left(1+0.34 u_{2}\right)}
$$

To calculate reference evapotranspiration (ETo), the FAO Penman-Monteith method depends on some parameters like:

- G soil heat flux density [MJ m-2 day-1 ],

- Rn net radiation at the surface [MJ m-2 day-1 ],

- $\mathrm{U} 2$ wind speed at $2 \mathrm{~m}$ height [m s-1 ],

- T air temperature at $2 \mathrm{~m}$ height $\left[{ }^{\circ} \mathrm{C}\right]$

- Es saturation vapour pressure [kPa],

- Ea actual vapour pressure [kPa],

- $\Delta$ slope of vapour pressure curve $\left[\mathrm{kPa}{ }^{\circ} \mathrm{C}-1\right]$,

- $\gamma$ psychrometric constant $\left[\mathrm{kPa}{ }^{\circ} \mathrm{C}-1\right]$.

There are some methods to evaluate the prediction accuracy of our proposed model based on Root Mean Square Error (RMSE), Mean Absolute Error (MAE), the determination coefficient $\left(\mathrm{R}^{\wedge} 2\right)$ [39].

$$
\begin{gathered}
R M S E=\sqrt{\frac{\sum_{i=1}^{N}\left(E T i_{\text {calculated }}-E T i_{\text {predicted }}\right)^{2}}{N}} \\
M A E=\frac{1}{N} \sum_{i=1}^{N}\left|E T i_{\text {calculated }}-E T i_{\text {predicted }}\right| 100 \\
R^{2}=1-\frac{\sum_{i=1}^{N}\left(E T i_{\text {calculated }}-E T i_{\text {predicted }}\right)}{\sum_{i=1}^{N}\left(E T i_{\text {calculated }}-\text { meanET }_{\text {predicted }}\right)^{2}}
\end{gathered}
$$

Where (ETi predicted) is the predicted value by the neural network model, (ETi calculated) is the value of ETo based on (FAO-56 PM ET), (N) is the number of observations [38].

We used also the multiple linear regression to predict the reference evapotranspiration with meteorological data, this data consists of some variables like the maximum and minimum temperature, humidity, wind speed, and solar radiation. By that the evapotranspiration represents the dependent variable (y), and the independent variables are climate data which are represented by $(\mathrm{x} 1, \mathrm{x} 2, \mathrm{x} 3, \mathrm{x} 4, \mathrm{x} 5)$, as expressed by following equation :

\section{$\mathbf{Y i}=\mathbf{b} 0+b 1 \times 1+b 2 \times 2+b 3 \times 3+b 4 \times 4+b 5 \times 5+e i$}

where yi and xi represent the observations of each of the variables $\mathrm{y}, \mathrm{x} 1, \ldots \mathrm{x} 5$ respectively, ei is a random error which is a term representing the remaining effects on [y] from the variables that are not explicitly included in the model, where b0, b1....b5 are fitting constant [41].

Our Hardware part of the proposed system designed based on seven types of sensors to monitor the weather and soil conditions, including soil moisture, soil temperature, humidity, wind speed, temperature, solar radiation and pressure as shown in Fig. 2. All these sensors are connected to the microcontroller,

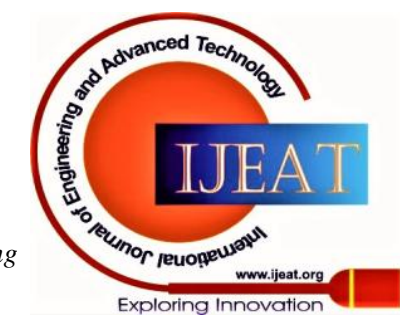




\section{Reference Evapotranspiration Prediction for Smart Irrigation}

and the microcontroller is connected to NRF24L01 [45]. The NRF24L01 is a half-duplex transceiver in which data is transferred in both directions. The NRF module transfer the collected data to the gateway. The gateway is consisting of raspberry $\mathrm{Pi} 3, \mathrm{NRF}$ module is connected to the internet through Ethernet cable. The gateway receives the collected data and upload it to the Thingspeak platform every 20 minutes [44].

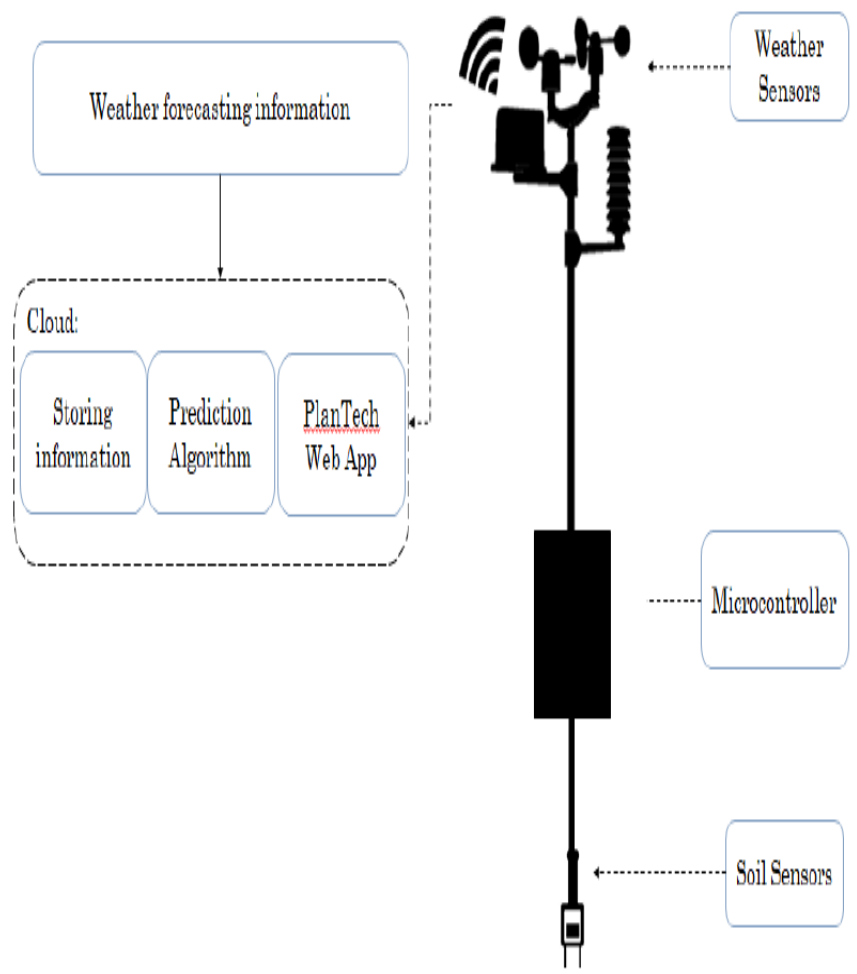

Fig. 2 Proposed hardware design of sensing and soil node

Our ANN and linear regression models described in previous sections are deployed to the cloud to predict the amount of water. Clloud will save the data, represent it to the farmer through dashboard and run the ANN model to predict the amount of water crop needs as shown in Fig. 1. At pump side the microcontroller receives control action from the model hosted on the cloud through the gateway and nRF module that represents the water amount crop needs and time to start irrigation. To predict weekly irrigation schedule, system need to forecasting weather data for 7 days, so system will use Open weather map API, this API is free and provide weather data about air temperature, humidity, wind speed, and sunrise and sunset time to calculate the solar radiation [43].

\section{IMPLEMENTATION AND TESTING}

The historical climate data split into $70 \%$ to train multiple linear regression model and $30 \%$ to test the model after the training. We used (RMSE), $(\mathrm{R} \wedge 2)$ and (MSE) metrices to assess the accuracy of the prediction model using test data to detect the best number of layers and nodes to achieve optimal values. The multiple linear regression model achieved (almost $\mathrm{R}^{\wedge} 2=0.68$ ) and (almost RMSE=3.01), that show that this model is weak in estimating reference evapotranspiration. Fig. 3 shows the relationship between the actual value as a blue point and fitted line that represents predicted value with almost 68.9\% accuracy [42].

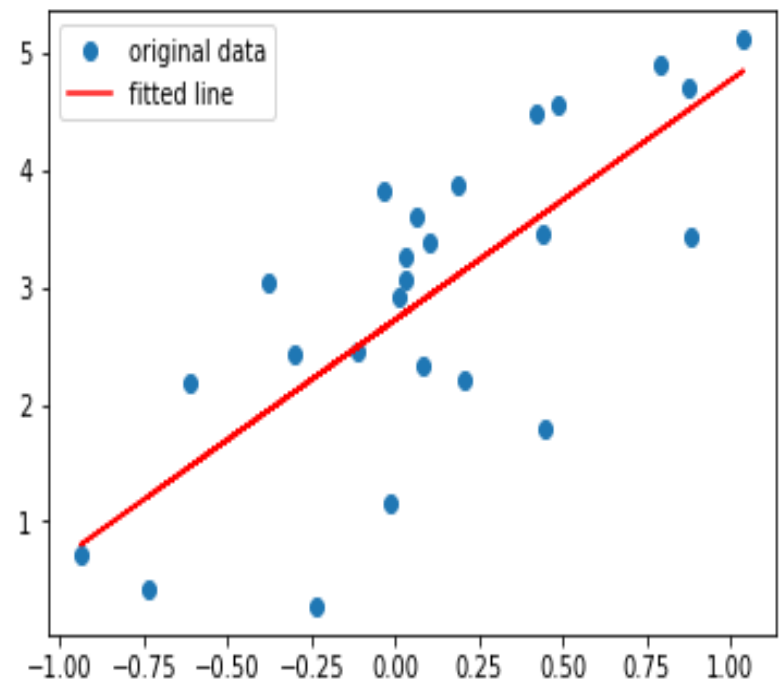

Fig. 3 relation between actual and prediction value using multiple linear regression

To build suitable neural network model , many different neural network models have been trained with the different number of hidden layers and nodes, after that (RMSE), $(\mathrm{R} \wedge 2)$ and (MSE) are calculated using test data to detect the best number of layers and nodes to achieve optimal case. The first model was trained by one hidden layer with 1 to 20 nodes, the best $\left(\mathrm{R}^{\wedge} 2\right.$ ) achieved was (almost $\mathrm{R}^{\wedge} 2=0.92$ ) and (almost $\mathrm{RMSE}=0.3$ ) with 12 nodes and one hidden layer, the second model, trained by 2 hidden layers with 12 nodes for each hidden layer and this model achieve (almost $\mathrm{R} \wedge 2=0.96$ ) and (almost RMSE $=0.12$ ), the models that trained with more than 2 hidden layers did not effect on the $\left(\mathrm{R}^{\wedge} 2\right)$ and (RMSE), so the best (RMSE )an $(\mathrm{R} \wedge 2)$ achieved by 2 hidden layers and 12 nodes in every layer. Fig. 4 shows the value of $(\mathrm{R} \wedge 2)$ after 600 epoch and represents how it is near to the optimal case that equal one. Fig. 5 shows the value of (RMSE) and how it is near to the optimal value that equal to 0 [49].

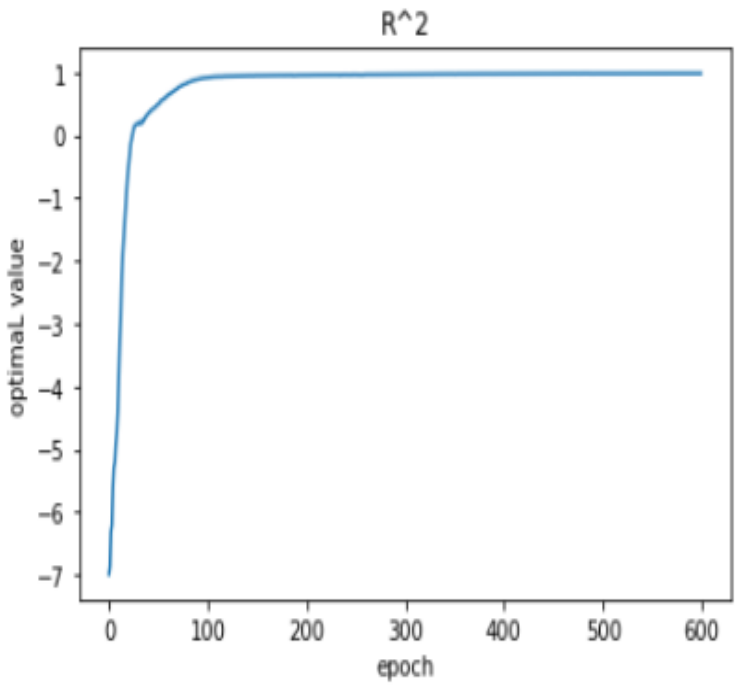

Published By:

Blue Eyes Intelligence Engineering and Sciences Publication (C) Copyright: All rights reserved. 
Fig. 4. Proposed system $A N N R \wedge 2$ results

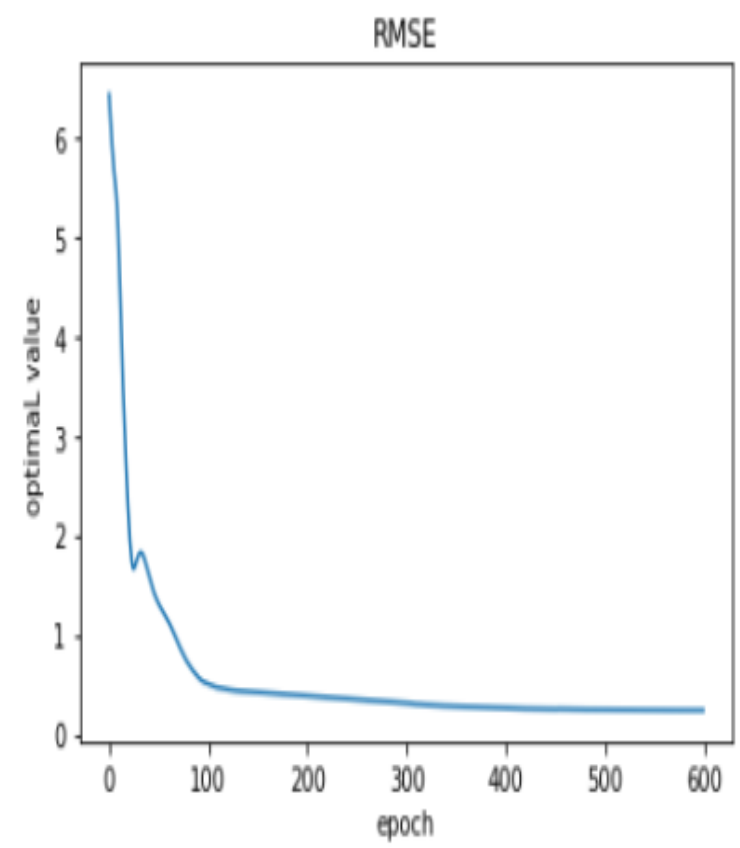

Fig. 5. Proposed system ANN RMSE results

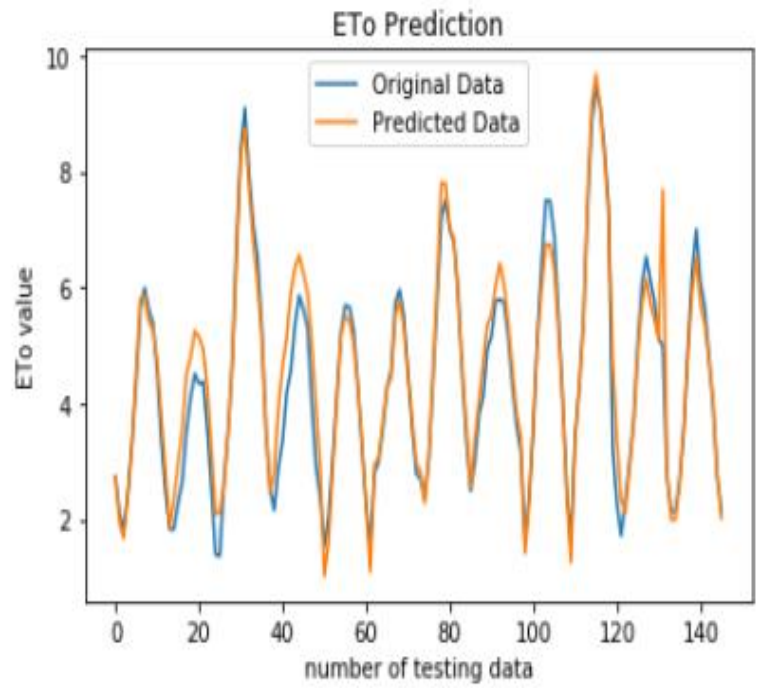

Fig. 6. Testing results of the ANN model

The $30 \%$ of data used for testing of neural network model (146 samples for daily weather data from 2017 to 2018) also used to compare between the predicted value and actual value from historical data to know the accuracy of the model.

Fig. 6 shows the comparison and the difference between predicted value by the neural network model and the actual value by testing data, orange graph represents the predicted value by the model and the blue graph represent actual value from testing data. This graph shows how the neural network mode based on Keras performed with achieved 97.8\% accuracy[50].

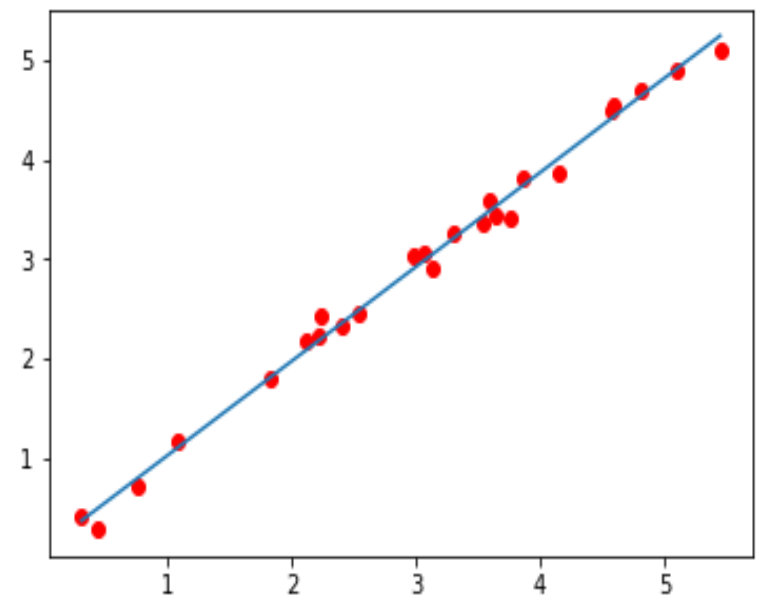

Fig. 7 Relation between actual and prediction value using ANN

As shown from Fig. 7, the relation between actual values as a red point and fitted line as a blue line and show the neural network performs very well to predict the reference evapotranspiration, the line represents the best condition and the point plotted on graph represent ETo. This paper used cropwat8.0 to test FAO 56 penman_monthein equation accuracy; the equation achieved low prediction accuracy; it achieved almost $\left(\mathrm{R}^{\wedge} 2=0.71\right)$ [48]. Fig. 8 shows the relation between predicted and actual value and show how penman_monthein equation perform very badly to predict accurate values.

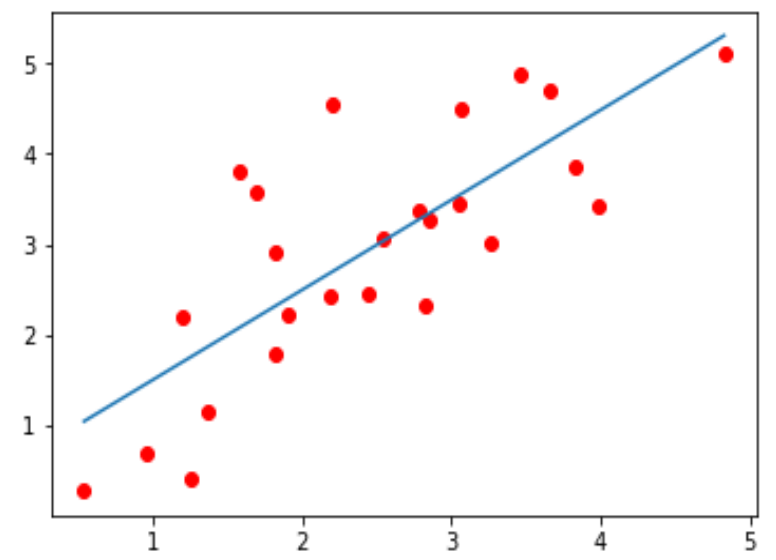

Fig. 8 Relation between actual and prediction value using FAO software (penman_monthein equation)

Thus, the ANN achieved very high accuracy compared with multiple linear regression and the FAO method. Accordingly, ANN model is very good to predict ETo with $\left(\mathrm{R}^{\wedge} 2\right)=0.96$ and can be used to make crop irrigation schedule. It also has the advanteges to decrease the number of variables that need to estimate ETo which reduces the complexity of hardware device and computation power needed for such complex calculations [46]. Table 1 shows the results of a simple regression analysis and presents the calculation of errors. The selected ANN model showed excellent performance when compared to ET_PM values.

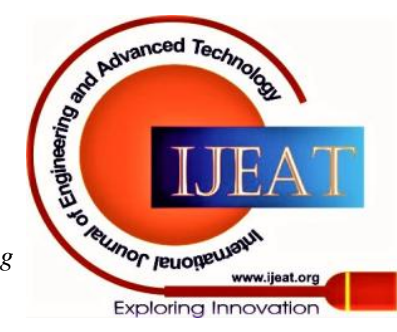




\section{Reference Evapotranspiration Prediction for Smart Irrigation}

This model with an RMSE of $0.16 \mathrm{~mm}$ d-1, an R2 of 0.96 and mean square error $(\mathrm{MSE})=0.0532$ and show the results of other models

Table 1. Benchmark comparison of proposed model

\begin{tabular}{|l|l|l|}
\hline method & $\mathbf{R} \wedge \mathbf{2}$ & $\mathbf{R M S E}\left(\mathbf{m m} \mathbf{d} \mathbf{d}^{\wedge} \mathbf{- 1}\right)$ \\
\hline Neural network & .96 & .12 \\
\hline Cropwat8.0 & .71 & .98 \\
\hline Linear regression & .68 & 3.01 \\
\hline
\end{tabular}

\section{CONCLUSION}

This paper focused on developing a SMART model for precision irrigation using both multiple linear regression and Artificial Neural Network (ANN) models based on Keras to predict reference evapotranspiration (ETo). The aim of the proposed model is to optimize the water efficiency and crop productivity. The proposed system used the IoT and ANN technology to predict water needs of any crop and create the weakly irrigation schedule using soil and meteorological measurements on real time from the farm. The testing analysis of the proposed system showed that the designed model achieved high accuracy compared with current model used by FAO or linear regression to predict ETo value with $(\mathrm{R} \wedge 2=0.96)$ and $(\mathrm{RMSE}=0.12)$ [47].

\section{ACKNOWLEDGMENT}

This paper and the research behind it would not have been possible without the engagement and support of MSA student Gamal Aldin whom I would like to thank and appreciate all his efforts, insights and expertise that greatly assisted through the course of this research. Finally, it is with true pleasure that I pay my sincere gratitude and acknowledgement for Gamal' contributions to achieve the research objectives as planned.

\section{REFERENCES}

1. A. Goldstein, L. Fink, A. Meitin, S. Bohadana, O. Lutenberg, and G. Ravid, "Applying machine learning on sensor data for irrigation recommendations: revealing the agronomist's tacit knowledge," Precision Agriculture, vol. 19, no. 3, pp. 421-444, 2017.

2. Y. Gandge and Sandhya, "A study on various data mining techniques for crop yield prediction,” 2017 International Conference on Electrical, Electronics, Communication, Computer, and Optimization Techniques (ICEECCOT), 2017.

3. M. Işı1k, Y. Sönmez, C. Yılmaz, V. Özdemir, and E. Yılmaz, "Precision Irrigation System (PIS) Using Sensor Network Technology Integrated with IOS/Android Application," Applied Sciences, vol. 7, no. 9, p. 891, Jan. 2017.

4. J. D., "Using Wireless Sensor Networks for Precision Irrigation Scheduling," Problems, Perspectives and Challenges of Agricultural Water Management, 2012.

5. Brevik EC, Fenton TE, Lazari A (2006) Soil Electrical Conductivity as a Function of Soil Water Content and Implications for Soil Mapping. Precision Agriculture

6. N. Suruthi, R. Saranya, S. Subashini, P. Shanthi, and A. Umamakeswari, "Managing Irrigation in Indian Agriculture Using Fuzzy Logic - A Decision Support System," International Journal of Engineering \& Technology, vol. 7, no. 2.24, p. 321, 2018

7. D. Lach, H. Ingram, and S. Rayner, "Coping with Climate Variability," Advances in Global Change Research Climate and Water, pp. 59-81, 2003

8. CHAPTER 3: CROP WATER NEEDS", Fao.org, 2019. [Online]. Available: http://www.fao.org/3/s2022e/s2022e07.htm. [Accessed: 19- Jun- 2019].

9. Fao.org, 2019. [Online]. Available: http://www.fao.org/3/a-ai593e.pdf. [Accessed: 19- Jun- 2019].

10. K.CVA,
"https://www.medwinpublishers.com/JOBD/JOBD16000139.pdf",

Journal of Orthopedics \& Bone Disorders, vol. 1, no. 7, 2017. Available: 10.23880/jobd-16000139.

11. 2019. [Online]. Available:

https://www.researchgate.net/publication/275038642_Prediction_of_ Evapotranspiration_using_Artificial_Neural_Network_Model. [Accessed: 19- Jun- 2019]

12. 2019. [Online].

Available: https://www.researchgate.net/publication/272024186_Root_mean_sq uare_error_RMSE_or_mean_absolute_error_MAE-_Arguments_agai nst_avoiding_RMSE_in_the_literature. [Accessed: 19- Jun- 2019].

13. 2019. [Online]. Available: https://www.researchgate.net/publication/260015447_A_Study_on_ Multiple_Linear_Regression_Analysis. [Accessed: 19- Jun- 2019].

14. 2019. [Online]. Available: https://www.researchgate.net/publication/324808725_An_improveme nt_of_the_convergence_proof_of_the_ADAM-Optimizer. [Accessed: 19- Jun- 2019].

15. 2019 . [Online]. Available: https://www.researchgate.net/publication/323956667_Deep_Learning _using_Rectified_Linear_Units_ReLU. [Accessed: 19-Jun- 2019].

16. Inf.ed.ac.uk, $2019 . \quad$ [Online]. Available: https://www.inf.ed.ac.uk/teaching/courses/nlu/assets/reading/Gurney_ et_al.pdf. [Accessed: 19- Jun- 2019].

17. [10]2019. [Online]. Available: https://www.researchgate.net/publication/269465138_Evaporation_a nd_Evapotranspiration. [Accessed: 19- Jun- 2019].

18. Optimizing Irrigation and Fertilization using Lysimeters," Israel Agricultural Technology Hub. [Online]. Available: http://www.israelagri.com/?CategoryID=520\&ArticleID=1498. [Accessed: 08-Dec-2018].

19. J. D., "Using Wireless Sensor Networks for Precision Irrigation Scheduling," Problems, Perspectives and Challenges of Agricultural Water Management, Sep. 2012.

20. R. Alcarria, T. Robles, A. Morales, and E. Cede no, "Resolving coordination challenges in distributed mobile service executions," International Journal of Web and Grid Services, vol. 10, no. 2, pp. 168-191, January 2014.

21. E. Serrano, P. Moncada, M. Garijo, and C. Iglesias, "Evaluating social choice techniques into intelligent environments by agent based social simulation," Information Sciences, vol. 286, pp. 102-124, December 2014.

22. L. Atzori, A. Iera, and G. Morabito, "The Internet of Things: A survey," Computer Networks, vol. 54, no. 15, pp. 2787-2805, October 2010.

23. D. Miorandi, S. Sicari, F. D. Pellegrini, and I. Chlamtac, "Internet of things: Vision, applications and research challenges," Ad Hoc Networks, vol. 10, no. 7, pp. 1497-1516, September 2012.

24. AENOR EN 62264: Enterprise-control system integration - Part 1 : Models and terminology, 2013

25. M. Melik-Merkumians, T. Baier, M. Steinegger, W. Lepuschitz, I. Hegny, and A. Zoitl, "Towards OPC UA as portable SOA middleware between control software and external added value applications," in Proc. Of the 17th IEEE Conference on Emerging Technologies and Factory Automation (ETFA'12), Krak'ow, Poland. IEEE, September 2012, pp. 1-8.

26. J. Imtiaz and J. Jasperneite, "Scalability of OPC-UA down to the chip level enables Internet of Things," in Proc. of the 11th IEEE International Conference on Industrial Informatics (INDIN'13), Bochum, Germany. IEEE, July 2013, pp. 500-505.

27. PSI Directive (2003/98/EC). Directive on the re-use of public sector information entered into force on 31 December 2003, European Commission.

28. Haider, Z. M., Malik, F. H., Rafique, M. K., Lee, S. J., Kim, J. H., Mehmood, K. K., Khan, S. U., and Kim, C. H., "An adaptive control of smart appliances with peak shaving considering EV penetration," in the transactions of the Korean institute of electrical engineers, vol. 65, no. 5, pp. 730-737, 2016.

29. Sortomme, E., Hindi, M. M., MacPherson, S. D. J., and Venkata, S. S., "Coordinated Charging of Plug-In Hybrid Electric Vehicles to Minimize Distribution System Losses," in IEEE Transactions on Smart Grid, vol. 2, no. 1, pp. 198-205, March 2011.

Published By: Blue Eyes Intelligence Engineering DOI:10.35940/ijeat.A1824.1010120

Journal Website: www.ijeat.orq

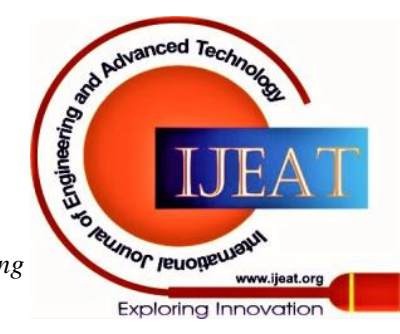


30. Liu, H., Zeng, P., Guo, J., Wu, H., Ge, S., “An optimization strategy of controlled electric vehicle charging considering demand side response and regional wind and photovoltaic," in Journal of Modern Power Systems and Clean Energy, vol. 3, no. 2, pp. 232-239, 2015.

31. Liu, M., McNamara, P., Shorten, R., McLoone, S., "Residential electric vehicle charging strategies: the good, the bad and the ugly," in Journal of Modern Power Systems and Clean Energy, vol. 3, no. 2, pp. 190-202, 2015

32. Ahn, C., Li, C. T., and Peng, H., "Decentralized charging algorithm for electrified vehicles connected to smart grid," Proceedings of the 2011 American Control Conference, San Francisco, CA, 2011, pp. 3924-3929.

33. Al-Awami, A. T., and Sortomme, E., "Electric vehicle charging modulation using voltage feedback control," 2013 IEEE Power and Energy Society General Meeting, Vancouver, BC, 2013, pp. 1-5.

34. Shinwari, M., Youssef, A., and Hamouda, W., "A Water-Filling Based Scheduling Algorithm for the Smart Grid," in IEEE Transactions on Smart Grid, vol. 3, no. 2, pp. 710-719, June 2012.

35. Shao, S., Pipattanasomporn, M., and Rahman, S., "Development of Physical-Based Demand Response- Enabled Residential Load Models," IEEE transactions on power systems, vol. 28, no. 2, pp. 607-614, 2013.

36. RELOAD Database Documentation and Evaluation and Use in NEMS [Online]. Available: http://www.onlocationinc.com /LoadShapesReload 2001.pdf.

37. Domestic hot water heater system modeling for the design of energy efficient systems [Online]. Available: www.allianceforwaterefficiency.org/WorkArea/linkit.aspx-?It emID=2256.

38. Kamienski, C. et al., "Application Development for the Internet of Things: A Context-Aware Mixed Criticality Systems Development Platform," Computer Communications, May 2017.

39. Kamilaris, A. et al., "Agri-IoT: A semantic framework for Internet of Things-enabled smart farming applications," IEEE WF-IoT 2016, December 2016.

40. López-Riquelme, J. A., "A software architecture based on FIWARE cloud for Precision Agriculture," Agricultural Water Management, March 2017.

41. Popović, T. et al., "Architecting an IoT-enabled platform for precision agriculture and ecological monitoring: A case study," Computers and Electronics in Agriculture, August 2017. EPA (2016) Climate Impacts on Water Resources. United States

42. Environmental Protection agency, Washington, DC. https://www. epa.gov/climate-impacts/climate-impacts-water-resources\#ref1.

Accessed 12 Mar 2017 Eskaf S (2015) Four trends in government spending on water and wastewater utilities since 1956. UNC Environmental Finance Center. http://efc.web.unc.edu/2015/09/09/four-trends-governmentspendingwater/. Accessed 5 Jan 2017

43. Gawlik BM, Easton P, Koop S, Van Leeuwen K, Elelman R (eds) (2017) Urban Water Atlas for Europe. European Commission, Publication Office of the European Union, Luxembourg

44. Folke C, Hahn T, Olsson P Norberg J (2005) Adaptive governance of social-ecological systems. Annu Rev Environ Resour, https://doi. org/10.1146/annurev.energy.30.050504.144511

45. Goldstein W, Peterson A, Zarrilli DA (2014) One city, rebuilding together: A report on the City of New York's response to Hurricane Sandy and the path forward. http://www1.nyc.gov/assets/ home/downloads/pdf/reports/2014/sandy_041714.pdf. Accessed 13 Sept 2016

46. Grimm NB, Faeth SH, Golubiewski NE, Redman CL, Wu J, Bai X, Briggs JM (2008) Global change and the ecology of cities. Science 319(5864):756-760. https://doi.org/10.1126/ science.1150195

47. Hausmann R, Hidalgo CA, Bustos S, Coscia M, Chung S, Jimenez J, Simoes A, Yildırım MA (2014) The Atlas of Economic Complexity. Cambridge, MA: Center for International Development/ MIT Media Lab

48. Hoekstra AY, Mekonnen MM, Chapagain AK, Mathews RE, Richter BD (2012) Global monthly water scarcity: blue water footprints versus blue water availability. PLoS ONE 7(2):e32688. https:// doi.org/10.1371/journal.pone.0032688

49. Kersbergen KV, Waarden FV (2004) 'Governance'as a bridge between disciplines: Cross-disciplinary inspiration regarding shifts in governance and problems of governability, accountability and legitimacy. Eur J Polit Res 43(2):143-171

50. Konikow LF (2013) Groundwater depletion in the United States (1900 -2008). U.S. Geological Survey Scientific Investigations Report 2013-5079

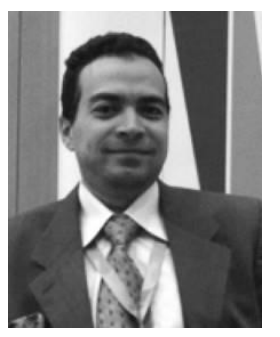

\section{AUTHORS PROFILE}

Dr. Samer Ibrahim was born in Gharbia, in 1976. He received the B.Sc. degree in computer engineering from the Ain Shams University, Egypt, in 1998, and the M.Sc. and Ph.D. degrees in Computer and system engineering from the computer and systems department, Ain Shams University, Egypt 2005 and 2009, respectively. He obtained his fellowship from Higher Education academy (HEA), UK in 2017. He is currently an Associate professor in MSA. Through his journey, Dr. Samer has many publications, patents researches, and books in international conferences and journals. Dr. Samer is a reviewer for many reputable journals and conference world-wide. He is an associate editor in an international journal of computer science and engineering. He has different roles through this journey not only on the academic level but on the industrial level as well. Dr. Samer has 20+ years of IT industrial experience in many international organizations as consultant and executive manager. Being a PMP certified for $12+$ and ITIL certified improved his academic, industrial and practical experience in leading and managing critical industrial projects in different technical domains. Dr. Samer traveled several times to foreign countries which offered better understanding of many cultures from east and west, enhanced his ability to get along with different nationalities and ethnic backgrounds. Through this industrial journey, he led many critical and biggest transformation projects/programs that affected the IT industry worldwide in multinational organization like Hewlett Packard with huge record of success stories/records

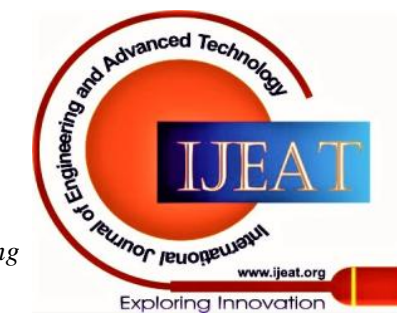

